\title{
Psicologia e Religião: um Encontro Inevitável
}

\author{
Psychology and Religion: an Inevitable Meeting
}

\author{
NiLTON Eliseu HERBES ${ }^{a}$
}

MIRIAM DE JeSUS E AVILA ${ }^{b}$

\section{Resumo}

Neste artigo, procuramos explorar as relações entre Psicologia e Religião e Psicologia e Teologia, trazendo o pensamento desenvolvido ao longo dos tempos por autores e autoras interessados na temática. Descrevendo os instrumentais destas ciências, a psicoterapia e a poimênica/aconselhamento pastoral, respectivamente, bem como suas diferentes abordagens, fica clara a existência de fatores de união e de divergência. Buscamos, numa leitura de textos de psicologia, identificar a proximidade e a importância do fenômeno religioso para a vida do ser humano e mostrar que essa não é uma ameaça à psicologia, bem como mostrar a influência da psicologia no fazer da poimênica/aconselhamento pastoral. O Sagrado possui uma importância inegável na constituição do ser humano e isso não deve ser negado por nenhuma das duas disciplinas. Psicologia e Teologia podem ser parceiras, sem ignorar a diferença existente quanto à intencionalidade de cada uma, mas respeitando suas visões específicas. Para tanto, procuramos definir o específico de cada uma das áreas e a sua contribuição no processo de ajuda e cuidado ao ser humano.

Palavras-chave: Psicologia. Teologia. Religião. Psicoterapia e Poimênica/Aconselhamento Pastoral.

\footnotetext{
a Escola Superior de Teologia (Faculdades EST), São Leopoldo, RS, Brasil. Doutor em Teologia, e-mail: nherbes@yahoo.com.br

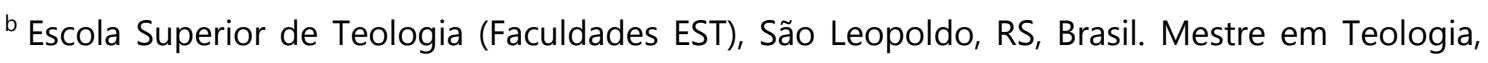
e-mail:mi.avila@yahoo.com.br
} 


\section{Abstract}

In this article, we seek to explore the relationship between Psychology and Religion and Psychology and Theology, bringing the thinking developed over time by authors interested in the subject. Describing the instrumentalities of these sciences, psychotherapy and poimenics/pastoral counseling, respectively, as well as their different approaches, it is clear the existence of factors of union and divergence. We seek, in a reading of psychology texts, to identify the proximity and importance of the religious phenomenon to the life of the human being and to show that this is not a threat to psychology, as well as to show the influence of psychology in the practice of pastoral counseling. The Sacred has undeniable importance in the constitution of the human being and this should not be denied by any of the two disciplines. Psychology and Theology can be partners, without ignoring the difference in the intentionality of each one, but respecting their specific visions. To do so, we try to define the specifics of each of the areas and their contribution to the process of helping and caring for the human being.

Keywords: Psychology. Theology. Religion. Psychotherapy and Poimenics/Pastoral Counseling.

\section{Introdução}

Enquanto ciência que estuda o fenômeno humano, à Psicologia interessa compreendê-lo em sua totalidade, na sua relação com o mundo, consigo mesmo e nas suas mais complexas ligações e coligações, sejam de ordem física, biológica, emocional, social, espiritual. Portanto, ela ultrapassa a questão do comportamento que, pretensamente, acredita-se poder ser medido, pesado e contado, o que a torna mais próxima da religião do que qualquer outra ciência.

Contudo, em seu início, a jovem e emergente Psicologia buscou aproximar-se das ciências naturais acreditando que, desta forma, encontraria o prestígio e o reconhecimento que buscava entre as demais ciências. Segundo Utsch, "a psicologia precisou seguir o Zeitgeist da revolução das ciências naturais e nadar junto na corrente da ciência objetiva" (UTSCH, 2013, p. 368), desvencilhando-se assim dos modelos de compreensão da alma humana de caráter filosófico e teológico (UTSCH, 2013, p. 368).

Com a Modernidade, noções de interioridade da alma, em que a vontade era "disputada entre o pecado e a fé, bem como discussões sobre o livrearbítrio deram lugar a um novo modelo de indivíduo: livre, autocentrado, 
medida de todas as coisas, dotado pela Razão do poder de conhecer (e dominar) o mundo e, em certa medida, associal" (DEGANI-CARNEIRO, JACÓVILELA, 2012, p. 71). Por algum tempo, ciência e religião ainda caminharam juntas neste período, uma vez que a regularidade do mundo era explicada em função de Deus, o elemento superior que, à semelhança da engrenagem de um relógio, daria início ao processo inferior, mecânico. Entretanto, no século XVIII, com o advento do lluminismo, ocorre o rompimento entre ciência e religião no mundo ocidental. A crença de que a Razão libertaria a humanidade dos mitos, da ignorância e da religião estabelece uma distinção radical entre o pensamento científico e as demais cosmovisões. Desta forma, a divindade perde sua centralidade no mundo ocidental, dando lugar aos discursos científicos, como o da Psicologia, no que tange à interioridade humana (DEGANI-CARNEIRO; JACÓ-VILELA, 2012, p. 71).

\section{Quando Psicologia dialoga com Religião}

Muitos estudiosos se debruçaram sobre a complexidade do fenômeno religioso, entre os quais se encontra William James (1842-1910) que, considerado por alguns como um dos pais da psicologia moderna, ao lado de Wilhelm Wundt ${ }^{1}$, talvez tenha dado a contribuição mais importante do pensamento do século XIX no que diz respeito ao diálogo entre psicologia/psiquiatria e religião. Como psicólogo experimental, ele aplicou a abordagem "viva-e-deixe-viver" à religião.

Ele descreveu em detalhes as conversões religiosas e seus benefícios psicológicos em seu livro The Varieties of Religious Experience, concluindo que, embora a religião esteja além da razão, a unidade dos testemunhos religiosos deixa aberta a possibilidade de que as crenças religiosas possam ser verdadeiras. Talvez sua mais importante contribuição para o diálogo entre a psicologia e a religião tenha sido sua declaração do direito do indivíduo de acreditar além da evidência (BLAZER, 2002, p. 75).

\footnotetext{
${ }^{1}$ Wilhelm Maximilian Wundt (1832-1920), médico, filósofo e psicólogo alemão. É considerado um dos fundadores da psicologia experimental junto com Ernst Heinrich Weber e Gustav Theodor Fechner.
} 
Wiliam James² descreveu duas categorias principais de pessoas: "as de 'mente sadia', ou 'nascidas uma vez'; e as de 'almas enfermas', ou 'nascidas duas vezes"” (HURDING, 1995, p. 25). Por "mente sadia”, ele compreendia os otimistas sem nenhuma ou quase nenhuma noção do pecado humano e que tinham uma busca insaciável pela felicidade. Embora este tipo de mentalidade pareça atraente, “James reconheceu que a realidade do mal e do pecado não permitem o sucesso no nível hedonístico para a maioria de nós" (HURDING, 1995, p. 25).

A despeito dessas percepções da natureza humana, James não era um cristão ortodoxo. Incapaz de aceitar 'tanto o cristianismo popular quanto o teísmo escolástico', ele entendia que sua posição era a de 'sobre-naturalismo bem dosado'. Sua visão era essencialmente a de um pragmático que descobriu que a ideia de um deus faz sentido na vida cotidiana (HURDING, 1995, p. 25).

No sentido oposto ao de James, John B. Watson (1878-1958), outro estudioso do comportamento humano e fundador do Behaviorismo ${ }^{3}$, acreditava que a religião era algo que pertencia ao passado e que se desenvolveu devido à ociosidade do ser humano, como uma desculpa para não ter que se esforçar por encontrar uma explicação para a ocorrência dos fenômenos. Para ele, a religião era uma ilusão forjada pelos padres nas mentes de pessoas tolas, uma venda que devia ser retirada e uma enfermidade que precisava ser curada (LEÓN, 1973, p. 20).

Já Carl Gustav Jung (1875-1961), considerado pai da Psicologia Analítica e discípulo de Freud, ${ }^{4}$ se deparou constantemente com o fenômeno religioso em suas investigações científicas em torno da mente humana profunda. Ele disse:

\footnotetext{
${ }^{2}$ William James (1842-1910) foi um filósofo e psicólogo americano. Considerado um dos principais pensadores do final do século XIX e por muitos rotularam de "pai da psicologia americana".

${ }^{3}$ Falaremos desta abordagem mais adiante, quando nos referirmos às bases teóricas da psicologia.

${ }^{4}$ A despeito da grande amizade e admiração que eles mantinham um pelo outro, a ponto de Freud considerar a possiblidade de Jung ser o seu sucessor, eles discordavam em pontos fundamentais. "Jung nunca foi capaz de aceitar a insistência de Freud de que as causas da repressão eram sempre traumas sexuais. Este último, por sua vez, ficava sempre apreensivo com o interesse de Jung pelos fenômenos mitológicos, espirituais e ocultos". (FADIMAN, 1986, p. 43).
} 
Visto que a religião constitui, sem dúvida alguma, uma das expressões mais antigas e universais da alma humana, subentende-se que todo o tipo de psicologia que se ocupa da estrutura psicológica da personalidade humana deve, pelo menos, constatar que a religião, além de ser um fenômeno sociológico ou histórico, é também um assunto importante para grande número de indivíduos (JUNG, 2012, p. 17).

Respeitando o rigor científico, Jung observou toda a espécie de manifestação religiosa tomada em sua extensão universal, abrangendo, portanto, as representações religiosas tanto do ser humano primitivo quanto das formas diversas de religiões que se manifestam nas fases mais avançadas da cultura humana, no ambiente, na cultura e nas tradições do Ocidente e do Oriente ao longo dos séculos. A partir dessas investigações, ele viu-se obrigado a reconhecer que a experiência religiosa é proveniente do inconsciente coletivo, de energias dinâmicas e símbolos de significados atemporais e universais, que escapam à consciência individual (UTSCH, 2013, p. 369).

Viktor Frankl (1905-1997) e sua escola psicológica de análise existencial chamada Logoterapia, "não apenas ampliam a questão psicológica para dentro da questão espiritual ou transcendental, como fazem desta o ponto central de todo o seu método terapêutico". Isso acontece na medida em que a questão da busca por sentido de vida torna-se a pergunta central do ser humano, "estribada numa antropologia que caracteriza o ser humano como um ser essencialmente orientado para o divino" ( $\mathrm{HOCH}, 1985$, p. 251, 252).

Para Frankl, a religião é um entre tantos fenômenos que ocorrem aos pacientes e precisa ser acolhida pelo terapeuta, seja ele religioso ou não. Ele afirma:

A religiosidade, conforme já dissemos, só é genuína quando existencial, quando a
pessoa não é impelida para ela, mas se decide por ela. Agora, porém, verificamos que
a essa característica de existencialidade devemos acrescentar uma segunda
característica, a da espontaneidade. À religiosidade verdadeira, para que seja
existencial, deve ser dado o tempo necessário para que possa brotar
espontaneamente. Nunca podemos apressar a pessoa nesse caminho (FRANKL, 2007,
p.69).

Mas não temos dúvida de que o autor que ficou mais conhecido por escrever a respeito da religião, no âmbito da psicologia, foi Sigmund Freud 
(1856-1939) que, à luz de sua teoria psicanalítica, tentou esclarecer as motivações psíquicas da experiência religiosa.

Nos inúmeros textos em que "Freud abordou o tema da religião, ele se propôs a elaborar uma interpretação psicanalítica da psicogênese e da natureza do fenômeno religioso, bem como analisar o significado dos ritos e do comportamento religioso" (MACIEL, 2008, p. 730).

No entanto, de acordo com Maciel e Rocha, houve uma vulgarização do pensamento de Freud sobre a religião ao longo da história do movimento psicanalítico. Expressões utilizadas por ele como: "a religião é uma ilusão", ou ainda "a religião é inimiga da ciência", contidas em alguns textos, ainda são utilizadas por muitos leigos ou mesmo conhecedores da Psicanálise para depreciar a religião e considerar Freud e a sua teoria como inimigos ferozes a serem combatidos. Por outro lado, por falta de um conhecimento mais completo e esclarecido da obra deste autor, foram desvalorizadas e esquecidas determinadas contribuições da psicanálise que poderiam enriquecer a compreensão metapsicológica do fenômeno religioso (MACIEL, 2008, p. 730)

Conforme Betty Fuks, Freud não pretendia unicamente depreciar a experiência religiosa à qual nunca aderiu, mas combater qualquer discurso que depreciasse o valor da vida e intimidasse a inteligência humana.

As baterias da psicanálise contra as religiões estão dirigidas muito mais às instituições religiosas que, através de seus "bezerros de ouro", subjugam e unificam os crentes, impedindo-os de pensar. De maneira explícita, Freud criticou tanto em seus textos quanto em documentos de sua vida particular o judaísmo, o cristianismo e até mesmo o budismo, em função dos efeitos negativos que promovem sob o sujeito, a ponto de levá-lo ao fanatismo religioso (FUKS, 2014, p. 120).

Diferente da lógica aristotélica das contradições excludentes e distinções rigorosas, o pensamento de Freud se apresenta em toda a sua obra como uma "sucessão de ideias que abrigam coincidência de opostos, aporias, problemas lógicos, contradições e paradoxos [...]", o que não é diferente quanto ao tema da religião (FUKS, 2014, p. 112).

\footnotetext{
${ }^{5}$ Para saber mais sobre as diferentes visões de Freud sobre a religião, consultar os seguintes artigos: Freud e a Religião: possibilidades de Novas Leituras e Construções Teóricas e Dois discursos de Freud sobre a religião, dos mesmos autores.
} 
Tal característica é percebida no pai da psicanálise quando constatamos que, dentre os muitos interlocutores com os quais ele se correspondeu estava Oskar Pfister (1873-1956), um pastor protestante, com quem Freud trocou cartas no período de 1909 a 1938. A Pfister, Freud afirmou:

\begin{abstract}
A psicanálise em si não é nem religiosa nem antirreligiosa, mas um instrumento apartidário do qual tanto o religioso como o laico poderão servir-se, desde que aconteça tão somente a serviço da libertação dos sofredores. Estou admirado de que eu mesmo não tenha me lembrado de quão grande auxílio o método psicanalítico pode fornecer à cura de almas, porém isto deve ter acontecido porque um mau herege como eu está distante dessa esfera de ideias (FREUD; MENG, 2009, p. 17).
\end{abstract}

É preciso acolher as observações do pai da psicanálise a respeito da religião para além do viés negativo, uma vez que há um número considerável de práticas religiosas que, em lugar de favorecer o crescimento humano, servem como uma desculpa para uma pessoa se esquivar dos reais problemas da existência.

A religião inextrincavelmente unida em seu nascimento aos sentimentos de culpabilidade, constitui o lugar onde ela pode nos armar as piores trapaças. A fé cristã pode se converter também em sua cúmplice e se aliar a seus elementos mais patogênicos. Desse modo, encerrada nos atoleiros do inconsciente, a fé pode converter-se num verdugo a serviço das pulsões de morte, traindo, assim, o que há de mais profundo em sua mensagem de liberdade (MORANO, 2003, p. 167).

Como podemos perceber acima, o estudo da religião dentro do campo da psicologia não é algo recente. O diálogo entre as duas ciências não tem sido tão fácil e pacífico, mas na contemporaneidade percebemos uma abertura maior para que ele aconteça.

\title{
Psicologia e Religião: diálogos contemporâneos
}

Atualmente, percebemos, por parte de alguns setores da Psicologia e da Psiquiatria, e até de outras especialidades dentro da medicina, uma abertura para a investigação do fenômeno religioso, assim como para um possível diálogo.

Paulo Dalgalarrondo, em seu livro Religião, Psicopatologia e Saúde Mental, afirma que, apesar da Psicologia, sobretudo a psicologia clínica, em 
algumas escolas ainda manter um profundo silêncio no que diz respeito à religião, à espiritualidade e à ideia de Deus, tem surgido um número crescente de médicos, médicas, psicólogos, psicólogas e demais pesquisadores no campo da saúde e dos transtornos mentais que têm pesquisado a religião como fenômeno humano recorrente e constitutivo da subjetividade e como uma das dimensões centrais da vida humana que, por esta razão, não deveria ser negligenciada (DALGALARRONDO, 2008, p. 20-25).

Marília Ancona-Lopez, outra estudiosa que há algum tempo se debruça sobre o tema, afirma que as religiões possuem conotações próprias na história dos indivíduos e na constituição de sua saúde mental. Por essa razão, ela está invariavelmente incluída em todo o atendimento clínico, mesmo se apenas implicitamente, e ignorá-la é perder um aspecto extremamente importante da formação pessoal (ANCONA-LOPEZ, 1999, p. 72). Aos psicólogos e psicólogas, segundo a autora, é imprescindível considerar as diferenças de sexo, status socioeconômico, características familiares, níveis educacionais, diferenças raciais e étnicas e, obviamente, das religiões enquanto componentes importantes da diversidade cultural. E, particularmente em relação à religiosidade, os profissionais precisam ter alguma familiaridade com as tradições religiosas e complementar seus conhecimentos com uma pesquisa clínica aprofundada da religiosidade singular de seu cliente. Tal conhecimento inclui "uma compreensão do envolvimento religioso na família de origem, da educação religiosa, das experiências formadoras de fé, das experiências geradas pelo contato com instituições, comunidades e tradições espirituais" (ANCONA-LOPEZ, 1999, p. 73, 74).

Para Edilson Souza, o sagrado, quando visto e acolhido pelo profissional que trata das angústias da alma humana e enquanto pertencente à história de cada indivíduo, merece ser ainda mais estudado como elemento capaz de auxiliar no processo de elaboração de conflitos e tensões do sujeito (SOUZA, 2006, p. 31).

Somente aqueles que se despirem de qualquer preconceito - seja com relação ao lugar da ciência na sociedade pós-moderna, ou com relação ao lugar do sagrado na experiência individual de cada ser - poderão desenvolver uma sensibilidade capaz de ouvir o outro em suas angústias; algumas articuladas pelos processos discursivos que trazem o sagrado. Sagrado que não precisa ser desqualificado como uma simples 
manifestação das disfunções e transtornos da alma, e sim como elemento integrador e reconciliador do homem consigo e com o semelhante (SOUZA, 2006, p. 31).

Considera-se então que, embora os diálogos entre teóricos do comportamento humano e estudiosos dos fenômenos religiosos tenham avançado significativamente nas últimas décadas, ainda existe um longo caminho a ser percorrido, aproximando e fazendo convergir ciência e religião.

\section{Teologia e Psicologia: cada um no seu lugar}

A História nos revela que nas sociedades primitivas a cura, independentemente se fosse de ordem psíquica ou física, era uma função exclusivamente religiosa. Isso porque se entendia a doença como sendo oriunda da ação de poderes sobrenaturais. Com o advento do pensamento científico e da descoberta das causas biológicas e naturais da doença, no entanto, a cura foi sendo desvinculada da influência de poderes sobrenaturais e, por conseguinte, da esfera de ação do sacerdote.

As doenças físicas e psíquicas passam então, de forma crescente, a ser da competência secular do médico e, "ao sacerdote, fica reservada a tarefa de ministrar à alma, considerada como uma esfera acientífica e atemporal do ser humano" (HOCH, 1985, p. 254, 255).

Esta dicotomia entre corpo e alma contribuiu decisivamente para a separação entre a função secular do médico e, mais tarde, da do psicólogo e a função religiosa do "cura d'almas". Aquilo que nas sociedades primitivas era uma unidade, passou a se constituir numa dualidade. Com isso a separação entre a medicina/psicologia, de um lado, e teologia/aconselhamento pastoral, de outro lado, era inevitável $(\mathrm{HOCH}, 1985$, p. 255).

A Psicologia, desde os seus primórdios, como já observamos, encontrava-se ocupada em desvencilhar-se de suas raízes teológicas e filosóficas. Por isso, ela prescreveu para si totalmente o ideal epistemológico das ciências naturais de medição e cálculo, para perfilar-se enquanto ciência social empírica, desafiando, desta forma, o poder interpretativo da Teologia em relação à natureza do ser humano. 
Compreensões adquiridas empiricamente através de enquetes e através do cálculo e interpretação de dados psicológicos ocuparam o lugar da antropologia filosófica e da exegese e hermenêutica teológica e trouxeram à tona novas imagens do ser humano. Com isso também surgiram ideais utópicos e modelos com cargas ideológicas (UTSCH, 2013, p. 373).

Não é de admirar, portanto, que a pesquisa acadêmica do caráter, que estava em vias de emancipar-se do ensino cristão sobre a alma, tenha se afastado da Teologia, uma vez que a Psicologia é, por definição, uma disciplina antropocêntrica, enquanto que a Teologia, assim como o aconselhamento pastoral, é vista como sendo de caráter teocêntrico. Isso significa que certas perguntas, fundamentais para as quais a Psicologia não pretende dar respostas, precisam ser respondidas pela Teologia $(\mathrm{HOCH}, 1985$, p. 257 e UTSCH, 2013, p. 369). Essa tendência de afirmar que o aconselhamento pastoral é teocêntrico o delimita muito, pois o mesmo se serve de todas as contribuições e técnicas da psicologia para ajudar o ser humano no seu relacionamento com o divino, estando, portanto, também atento ao dinamismo e comportamento do ser humano.

Para Jorge Ponciano Ribeiro, não compete à Psicologia estudar Deus enquanto um objeto específico de conhecimento, tampouco ocupar-se com o relacionamento da pessoa com Deus, pois tal fato pertence à Teologia e à Teodiceia. Quem espera isso da Psicologia está sobrecarregando-a com uma tarefa que ela mesma não pretende considerar como sendo de sua competência. Cabe à Psicologia, seguindo a trilha de suas origens filosóficas que estavam à procura de Deus, colocar-se na posição de escuta compartilhada e compromissada com milhares de clientes que têm, contida (às vezes de modo consciente, às vezes inconsciente) em sua demanda por atendimento, a ideia de Deus como mantenedora, doadora e organizadora do sentido de suas vidas (HOLANDA, 2015. p. 19; HOCH, 1985, p. 257).

O que vemos, porém, é que

a Psicologia tem medo de perder sua cientificidade se introduzir Deus como um dos objetos de suas preocupações acadêmicas. Tornou-se, assim, prisioneira de suas próprias certezas. Não pode aceitar a ideia de Deus, porque não pode comprovar sua existência; não pode negá-la, porque bilhões de inteligências humanas convivem com a ideia de um Ser Superior. E aí a Psicologia ou uma certa psicologia tem feito a pior coisa que uma ciência pode fazer: faz de conta que Deus não é objeto de suas preocupações epistemológicas (HOLANDA, 2015, p. 15). 
Como consequência, conforme o teólogo e psicólogo Michael Utsch, o diálogo entre Psicologia e Teologia tem se arrastado porque, em muitos contextos ainda, elas se contrapõem como rivais quanto à sabedoria da vida, justamente porque o que está em jogo é o protagonismo em relação à necessidade interpretativa e explicativa do cotidiano: um acontecimento deve ser interpretado sob o viés psicológico-imanente ou, em sentido amplo, sob uma perspectiva religioso-transcendente? (UTSCH, 2013, p. 372).

Utsch revela que na Alemanha, em alguns aspectos, a Teologia sofreu uma perda de relevância significativa nas últimas décadas. Em contrapartida, interpretações psicológicas souberam tirar proveito dessa perda de significado da compreensão da realidade a partir do horizonte eclesial-cristão e, hoje em dia, ostentam, em parte, sem constrangimento algum, como instâncias de atribuição de sentido e como normas de orientação (UTSCH, 2013, p. 372).

\footnotetext{
Suspeitas da Psicologia em relação à teoria teológica sobre a pessoa foram formuladas no sentido de que a perspectiva teológica pouco valoriza a sensualidade e a corporeidade do ser humano e produz doenças obsessivo-compulsivas com suas ideias morais rígidas e alheias ao mundo. Já suspeitas de parte da Teologia em relação à Psicologia foram, por exemplo, formuladas no sentido de que lá se praticaria um culto sistemático em torno do próprio ego (UTSCH, 2013, p. 373).
}

Vemos então que, neste diálogo entre o teológico e o psicológico, existe um vasto temário e um extenso caminho a percorrer. Conforme Jorge Léon, o pastor não é um intruso quando percorre o campo psicológico, uma vez que o cuidado das almas e das mentes, como já pudemos verificar, foi uma função exclusivamente religiosa por vários milênios, assim reconhecida por representantes famosos da psicologia e da psiquiatria (LEÓN, 1996, p. 18).

Sendo assim, Utsch defende que para ser possível um diálogo crítico recíproco entre a Psicologia e a Teologia, ambas precisam apontar uma para os limites da outra: a Teologia para a questão das premissas antropológicas e cosmovisivas que servem de fundamento à Psicologia, e esta para os aspectos fundamentais do sentir, pensar e agir religioso, muitas vezes ignorado por aquela (UTSCH, 2013, p. 364).

Para Lothar Hoch, o autoconhecimento da pessoa humana e suas motivações mais profundas precisam fazer parte das preocupações de uma 
Teologia que acentua a historicidade e a falibilidade de toda a ação humana. Desta forma, a Psicologia pode ajudar o teólogo (e o não teólogo) a refletir criticamente e também a se conscientizar de suas limitações e necessidades, bem como dos condicionamentos psicológicos que o escravizam. Não os considerar é enganar-se a si mesmo, o que pode fazer da Teologia uma cúmplice na fuga do teólogo de um confronto consigo mesmo. "A encarnação de Cristo não se deu apenas para dentro de contextos sofridos da sociedade; ela se deu também para dentro das profundezas mais escuras da nossa individualidade" ( $\mathrm{HOCH}, 1985$, p. 250).

O aconselhamento pastoral não precisa ter receio de se tornar herético quando coloca a pessoa humana no centro de suas preocupações. Também Deus se fez homem para resgatar a pessoa humana em toda a profundeza da sua humanidade. Só que, ao contrário da psicologia, a teologia e o aconselhamento pastoral não se limitam à dimensão antropológica da pessoa. O antropocentrismo é apenas provisório e instrumental. O objetivo último do aconselhamento é a relação da pessoa com Deus $(\mathrm{HOCH}, 1985$, p. 257, 258).

Para o psiquiatra Dan Blazer, "as crenças e ações religiosas, assim como o sofrimento emocional, são urdidas no mesmo tecido da história de vida de uma pessoa" (BLAZER, 2002, p. 249). Consequentemente, muito do que temos aprendido através das ciências psicológicas, como estudos sobre a memória, desenvolvimento da personalidade, crescimento social e intelectual e transições críticas da vida (como a adolescência), entre outros conhecimentos, e que nos informam sobre o funcionamento do ser humano, precisam ser integrados à história de vida de uma pessoa, incluindo aí também a sua história espiritual (BLAZER, 2002, p. 249, 250).

Desta forma, Psicologia e Teologia têm seu lugar e importância no auxílio que podem oferecer ao ser humano. Pretender que a "assistência médica da alma", como afirma Frankl, substitua a "assistência pastoral da alma", é ignorar a diferença existente quanto à intencionalidade de cada uma destas disciplinas (FRANKL, 2007, p. 71). 


\section{Psicoterapia ou Aconselhamento Pastoral?}

Para que possamos responder esta pergunta, precisamos delimitar o campo de atuação e o papel de cada uma no tocante ao auxílio que elas podem oferecer às pessoas em sofrimento, tendo em vista que tanto a Psicologia quanto a Teologia ocupam-se igualmente do mesmo ser humano e de sua libertação, apesar de, em alguns ambientes, elas ainda se mostrarem como “rivais quanto à sabedoria da vida" (JUNG, 2012, p. 372). Haveria então como nos beneficiarmos destes dois conhecimentos?

\section{Psicoterapia: uma ferramenta da Psicologia}

Em meados do século XIX, com o objetivo de tratar, remover ou modificar sintomas de natureza emocional e promover o crescimento e o desenvolvimento da personalidade, surgem as psicoterapias no Ocidente. Estas variam em relação às escolas filosóficas, às perspectivas epistemológicas, às teorias e aos métodos que utilizam como orientação de suas intervenções práticas (PERES; SIMÃO; NASELLO, 2007, p. 137).

Quanto às diferenças, similaridades e eficácia das terapias, Peres, Simão e Nasello apontam que, entre a publicação do artigo "Some implicit common factors in diverse methods of psychotherapy" por Rosenzweig em 1936, até a discussão sobre o tema, realizada por Goldfried em 1999, o mesmo dado foi encontrado: existe pouca ou nenhuma diferença entre as principais escolas de psicoterapia em termos de efetividade global.

Atualmente, o que se conclui é que

as áreas de concordância entre as abordagens psicoterápicas continuam mais expressivas que as diferenças, sobressaindo em especial quatro aspectos: a similaridade dos objetivos; a relação terapeuta-cliente tem papel central nos processos; o cliente responsabiliza-se pelas escolhas; e a promoção da compreensão do "eu" pelo cliente (PERES; SIMÃO; NASELLO, 2007, p. 137, 138).

Consequentemente, por razões históricas e também doutrinárias, é impossível à Psicologia uma unidade metodológica. Sendo assim, ao invés de 
falarmos em "Psicologia", talvez fosse preferível falarmos em "ciências psicológicas", porque podem especificar ao mesmo tempo

\begin{abstract}
tanto um domínio de pesquisa (psicologia diferencial), um estilo metodológico (psicologia clínica), um campo de práticas sociais (orientação, reeducação, terapia de distúrbios comportamentais etc.), quanto determinada escola de pensamento que chega a definir, para seu próprio uso, tanto sua problemática quanto seus conceitos e instrumentos de pesquisa. [...] Donde não haver nenhum inconveniente em falarmos de "psicologias" no plural. Numa época de mutação acelerada como a nossa, a Psicologia se situa no imenso domínio das ciências "exatas", biológicas, naturais e humanas. Há diversidade de domínio e diversidade de métodos. Uma coisa, porém, precisa ficar clara: os problemas psicológicos não são feitos para os métodos; os métodos é que são feitos para os problemas (JAPIASSU, 1983 apud BOCK; FURTADO; TEIXEIRA, 2008, p. 30).
\end{abstract}

Conforme Bock, as três grandes teorias ou sistemas teóricos responsáveis pelas matrizes da Psicologia contemporânea são: a Psicanálise, a Gestalt e o Behaviorismo (BOCK; FURTADO; TEIXEIRA, 2008, p. 90). De uma forma muito resumida, descreveremos cada uma destas abordagens teóricas aqui.

A Psicanálise é tanto uma teoria da personalidade quanto um método de psicoterapia. Seu fundador, Sigmund Freud, privilegiou o estudo do inconsciente. Ele acreditava que os desejos inaceitáveis (proibidos ou castigados) da infância são retirados da percepção consciente e tornam-se parte do inconsciente, onde continuam a influenciar nossos pensamentos, sentimentos e ações. Pensamentos inconscientes são expressos de várias formas: sonhos, erros de linguagem e peculiaridades de comportamento (ATKINSON et al., 2002, p. 31).

Freud usava o método de associação livre, no qual o paciente era instruído a dizer tudo o que ele estivesse pensando naquele momento, como uma forma de acessar o inconsciente e de lá trazer o seu conteúdo para a consciência. Na teoria freudiana clássica, as motivações por trás dos desejos inconscientes quase sempre envolviam sexo ou agressão. Por esse motivo, a Psicanálise enfrentou muita resistência quando foi proposta pela primeira vez. No entanto, ainda que a maioria dos psicólogos contemporâneos não aceitem totalmente a concepção de inconsciente de Freud, "eles tendem a concordar que os indivíduos não têm plena consciência de alguns aspectos importantes de seu comportamento" (ATKINSON et al., 2002, p. 31). 
Como explica Atkinson, Gestalt é uma palavra alemã que significa "forma” ou "configuração", e foi usada para designar a abordagem criada por Max Wertheimer e seus colegas Kurt Koffka e Wolfgang Köhler. Os psicólogos da Gestalt estavam interessados na percepção "e acreditavam que as experiências perceptivas dependiam dos padrões formados pelos estímulos e da organização da experiência" (ATKINSON et al., 2002, p. 31).

O que vemos está relacionado com o pano de fundo contra o qual aparece um objeto, bem como com outros aspectos do padrão geral de estimulação. Assim, o todo é diferente da soma de suas partes, uma vez que o todo depende dos relacionamentos entre as partes (ATKINSON et al., 2002, p. 31).

Estes interesses na percepção do movimento, em como as pessoas avaliam o tamanho e na aparência das cores com diferente iluminação, levaram a "diversas interpretações centradas na percepção da aprendizagem, da memória e da resolução de problemas que ajudaram a estabelecer as bases para a atual pesquisa em psicologia cognitiva" (ATKINSON et al., 2002, p. 31).

O Behaviorismo, cujo fundador é John B. Watson ${ }^{6}$, constitui um ramo puramente objetivo da Ciência Natural, e teve maior influência na psicologia científica na América do Norte. Seu objetivo teórico é a predição e o controle do comportamento. "Watson afirmava que quase todo o comportamento é resultado do condicionamento e que o ambiente molda o comportamento reforçando hábitos específicos" (ATKINSON et al., 2002, p. 30. Cf. FADIMAN, 1986, p. 191).

Desde Watson, o termo "comportamento" não se refere somente a uma ação isolada de um sujeito, mas a uma interação entre aquilo que o sujeito faz e o ambiente onde ele executa a sua ação. Portanto, "o Behaviorismo dedica-se ao estudo das interações entre o indivíduo e o ambiente, entre as ações do indivíduo (respostas) e o ambiente (estimulações)" (BOCK; FURTADO; TEIXEIRA, 2008, p. 59).

\footnotetext{
${ }^{6}$ A pesquisa do fisiólogo russo Ivan Pavlov sobre a resposta condicionada era considerada uma área importante da pesquisa comportamental, mas foi Watson o responsável pela ampla influência do Behaviorismo (cf. ATKINSON et al., 2002, p. 30).
} 
Haveria ainda muitas outras abordagens teóricas e psicoterápicas as quais poderíamos explicitar, no entanto, devido ao espaço resumido, preferimos destacar as que deram fundamento para as teorias posteriores.

\section{Poimênica ou Aconselhamento pastoral: ferramentas da Teologia}

O termo "aconselhamento pastoral", traduzido para o português da expressão em inglês pastoral counseling, e muito utilizada no contexto norteamericano do século $X X$, é considerada por muitos como uma expressão problema, pois sugere

que aconselhamento seria em primeiro lugar uma atividade do pastor como ministro ordenado e implicaria uma relação de poder que não deixa espaço para a livre articulação do seu parceiro de comunicação e para o desenvolvimento independente do mesmo (SCHNEIDER-HARPPRECHT, 2011, p. 256).

Outros termos técnicos usados neste contexto são: poimênica, do grego poimen, que significa "a ciência do agir do pastor", clínica pastoral, que diz respeito ao "acompanhamento pastoral na área da saúde" e psicologia pastoral, que contempla "a interpretação da pastoral sob a perspectiva psicológica”. Quanto às expressões usadas para designar aqueles e aquelas que são parceiros e parceiras na conversação, estão: paciente, cliente e aconselhando ou aconselhanda.

Conforme Schneider-Harpprecht, todas estas palavras têm a sua origem na medicina, na psicanálise e no método psicoterápico de Carl Rogers ${ }^{7}$ e designam uma relação de poder.

A tendência de entender a atividade do aconselhamento pastoral a partir da medicina tem as suas raízes já na igreja antiga e deve-se à tradição do platonismo, que transparece no conceito clássico de cura d'almas, o qual entende como tarefa principal do pastor a salvação da alma imortal através da confissão e absolvição (SCHNEIDER-HARPPRECHT, 2011, p. 256).

\footnotetext{
7 "Carl Rogers é conhecido por uma abordagem popular de psicoterapia denominada terapia centrada na pessoa ou terapia centrada no cliente. Atribuindo a responsabilidade da mudança à pessoa ou cliente, e não ao terapeuta [...]. Rogers supôs que as pessoas podem alterar consciente e racionalmente seus pensamentos e comportamentos indesejáveis, tornando-os desejáveis" (SCHULTZ; SCHULTZ, 1981, p. 397, 398).
} 
Para o autor, este problema do "poder" precisa ser relativizado, pois essa atividade, além de não ter que se restringir apenas aos ministros e ministras ordenados, deve-se constituir em uma relação livre entre dois parceiros iguais. ${ }^{8}$ Sendo assim, ele define a poimênica e o aconselhamento pastoral da seguinte forma:

Definimos a poimênica como o ministério de ajuda da comunidade cristã para os seus membros e para outras pessoas que a procuram na área da saúde através da convivência diária no contexto da igreja, e definimos o aconselhamento pastoral como uma dimensão da poimênica que procura ajudar através da conversação e outras formas de comunicação metodologicamente refletidas (SCHNEIDERHARPPRECHT, 2011, p. 256).

Schneider-Harpprecht acrescenta ainda que os principais objetivos do aconselhamento pastoral são: descobrir com as pessoas o significado concreto da liberdade cristã de seres humanos pecadores, cujo direito de viver e cuja aceitação vêm da graça de Deus, e ajudá-las para que possam viver, de uma maneira consciente e adulta, a sua relação com Deus, consigo mesmas e com o próximo (SCHNEIDER-HARPPRECHT, 2011, p. 256).

Dessa forma, a poimênica e o aconselhamento pastoral revelam-se "como uma expressão da vida da comunidade e não como uma tarefa reservada para pastores, pastoras ou outros especialistas da igreja" (SCHNEIDER-HARPPRECHT, 2011, p. 257). Trata-se de uma forma específica do discurso humano, cujo fundamento social é a convivência no contexto da igreja ${ }^{9}$, a koinonia (comunhão) dos membros, que tem, para os cristãos e cristãs, um significado espiritual: na convivência da comunidade acontece a comunhão com Jesus Cristo, o Filho de Deus encarnado que se torna presente "onde dois ou três se reúnem no nome dele" (SCHNEIDER-HARPPRECHT, 2011, p. 257).

\section{Considerações finais}

Quando nos propomos a falar dos pontos comuns e das diferenças entre Psicoterapia e Aconselhamento Pastoral, estamos considerando que de ambas

\footnotetext{
8 "Parceiros iguais" fala de uma relação simétrica.

${ }^{9} \mathrm{O}$ termo Igreja, aqui, refere-se aos membros de uma congregação religiosa. 
as partes existem possibilidades e limites. No ato de reconhecer os méritos de uma das disciplinas, não estamos desprezando a qualidade da outra. Ambas as áreas possuem sua relevância. Nenhuma é possuidora da fórmula última para acompanhar as pessoas em todas as suas crises e desafios.

Tanto a Psicoterapia como o Aconselhamento Pastoral são tentativas humanas e, por isso, limitadas em auxiliar na resolução de todos os problemas e crises. Sendo assim, atitudes arrogantes e autossuficientes de lado a lado não irão contribuir na tarefa comum de auxiliar aqueles e aquelas que sofrem. Por outro lado, diluir diferenças e deixar de apontar de uma forma clara, crítica e objetiva as limitações, as possibilidades e as características de cada uma dessas disciplinas não é o melhor caminho a ser seguido.

Aceitar a forma abreviada de dizer que a Psicoterapia tem a ver com a "cura" e o Aconselhamento Pastoral com a "salvação", é não compreender que existem pontos em comum e sobreposições entre estas duas disciplinas. O Aconselhamento Pastoral não possui somente um diálogo sobre as questões de fé e crises espirituais em seus acompanhamentos. Em muitos casos, a proclamação direta do Evangelho não existe, pois os conflitos tratados são, como ocorre na psicoterapia, relacionados a conflitos relacionais, de papéis sociais, de crises de identidade. Assim como questões de culpa, perdão, biografia e crises de fé que poderiam ser consideradas domínio da Teologia, também se apresentam em atendimentos da Psicologia. Os mesmos conflitos de valores se apresentam tanto para pessoas religiosas quanto para profissionais da psicologia.

Portanto, ambas as áreas possuem seu específico e seu público de atendimento. Não há motivos para rivalidades. A Psicologia e a Teologia estão preocupadas com o cuidado do ser humano em sua integridade. $\mathrm{Na}$ contemporaneidade, com todos os seus dilemas e desafios, as pessoas necessitam de diferentes formas de ajuda para encontrar o caminho que, no final, elas mesmas escolhem, conduzindo-as à felicidade e à realização, tanto pessoal como no contexto de suas relações. 


\section{Referências}

ANCONA-LOPEZ, M. Religião e psicologia clínica: quatro atitudes básicas. In: MAHFOUD, M.; MASSIMI, M. (Org.). Diante do mistério - Psicologia e senso religioso. São Paulo: Loyola, 1999.

ATKINSON, R. L. et al. Introdução à psicologia de Hilgard. Porto Alegre: Artmed, 2002.

BLAZER, D. Freud versus Deus. Tradução de Paulo Zacarias. Viçosa: Ultimato, 2002.

BOCK, A. M. B.; FURTADO, O.; TEIXEIRA, M. L. T. Psicologias: uma introdução ao estudo da psicologia. São Paulo: Saraiva, 2008.

DALGALARRONDO, P. Religião, psicopatologia e saúde mental. Porto Alegre: Artmed, 2008.

DEGANI-CARNEIRO, F.; JACÓ-VILELA, A. M. Religião na história da psicologia no Brasil: o caso do protestantismo. Diaphora, v. 11, n. 1, p. 70-79, 2012.

FADIMAN, J.; FRAGER, R. Teorias da personalidade. Tradução de Camila Pedral Sampaio e Sybil Safdié. São Paulo: HARBRA, 1986.

FRANKL, V. E. A presença ignorada de Deus. Tradução de Walter O. Schlupp e Helga H. Reinhold. 10. ed. São Leopoldo/Petrópolis: Sinodal/Vozes, 2007.

FREUD, E. L.; MENG, H. (Org.). Cartas entre Freud \& Pfister (1909-1939): um diálogo entre a psicanálise e a fé cristã. Tradução de Karin Hellen Kepler Wondracek e Ditmar Junge. 3. ed. Viçosa: Ultimato, 2009.

FRIESEN, A. Cuidando do ser: treinamento em aconselhamento pastoral. Curitiba: Esperança, 2002.

FUKS, B. B. O homem Moisés e a religião monoteísta - Três ensaios: O desvelar de um assassinato. Rio de Janeiro: Civilização Brasileira, 2014.

HOCH, L. C. Psicologia a Serviço da Libertação: possibilidades e limites da psicologia no aconselhamento pastoral. Estudos Teológicos, São Leopoldo, ano 25, n. 3, 249-269, 1985.

HOLANDA, A. F. (Org.). Psicologia, religiosidade e fenomenologia. 2. ed. Campinas: Editora Alínea, 2015.

HURDING, R. F. A árvore da cura: fundamentos psicológicos e bíblicos para aconselhamento cristão e cuidado pastoral. Tradução de Márcio Loureiro Redondo. São Paulo: Vida Nova, 1995.

JUNG, C. G. Psicologia e religião. Tradução de Mateus Ramalho Rocha. Revisão técnica de Dora Ferreira da Silva. 11. ed. Petrópolis: Vozes, 2012. 
LEÓN, J. A. Psicología de la experiencia religiosa. Buenos Aires: Editorial Caribe, 1973.

LEÓN, J. A. Introdução à Psicologia Pastoral. Tradução de Ruth Maria Maestre. São Leopoldo: Sinodal, 1996.

MACIEL, K. D. S. A.; ROCHA, Z. J. B. Dois discursos de Freud sobre a religião. Revista Mal-estar e subjetividade, Fortaleza, v. 8, n. 3, p. 729-754, set. 2008.

MACIEL, K. D. S. A.; ROCHA, Z. J. B. Freud e a religião: possibilidades de novas leituras e construções teóricas. Revista Psicologia, ciência e profissão, v. 28, n. 4, p. 742-753, 2008.

MORANO, C. D. Crer depois de Freud. São Paulo: Loyola, 2003.

PERES, J. F. P.; SIMÃO, M. J. P.; NASELLO, A. G. Espiritualidade, religiosidade e psicoterapia. Rev. psiquiatr. clín., São Paulo, v. 34, n. supl. 1, p. 136-145, 2007.

RAUCHFLEISCH, U. Quem cuida da alma? Controle de fronteiras entre psicoterapia e poimênica. São Leopoldo: Sinodal/EST, 2014.

SCHNEIDER-HARPPRECHT, C. (Org.). Teologia Prática no contexto da América Latina. 3. ed. rev e ampl. São Leopoldo: Sinodal/Est, 2011.

SCHULTZ, D. P.; SCHULTZ, S. E. História da psicologia moderna. São Paulo: Cultrix, 1981.

SOUZA, E. S. O Sagrado, o sujeito e a psicoterapia. Via Teológica, Curitiba, v. 1, n. 13, p. 23-32, jun. 2006.

UTSCH, M. Religião e Psicologia. Estudos Teológicos, São Leopoldo, v. 2, n. 53, p. 364381, jul/dez 2013. 